\title{
A SIMULATION STUDY OF COOLING SYSTEM FOR HEAVY DUTY DIESEL ENGINE
}

\author{
Pranita Adsul ${ }^{1}$, Vinod Kotebavi $^{1}$, Sanjeev Bedekar ${ }^{2}$, and Ashwini Mishra ${ }^{2}$ \\ ${ }^{1}$ Department of Mechanical Engineering, Amrita School of Engineering, Bengaluru, Amrita Vishwa Vidyapeetham, India \\ ${ }^{2}$ Cummins India Office Campus, Balewadi, Pune, Maharashtra-411045, India
}

\begin{abstract}
The main function of the cooling system is to control the temperature of the engine components and improve the performance of an engine. To know the flow and temperature distribution in the jacket cooling system for 6 cylinder diesel engine is analyzed using 1 dimensional method by using GT-Suite 1D simulation software package. The present work employs 1D simulation of water jacket in GT-ISE to perform a comprehensive study of mass-flow and thermal distribution over the inlet of the cooling package of a selected engine in several steady state operating points. The results show, that the suggested predictive method successfully captures the thermal effect of recirculation while reducing the necessity for calibration done by prototype testing.

Keywords. GT-Suite, 1 Dimensional, Calibration, water-jacket.
\end{abstract}

\section{INTRODUCTION}

The role of engine cooling system is to take away heat fast enough to keep the engine material temperature well below its melting point and increase the durability of engine [1]. Complexity of cooling system of a vehicle increases with the advancement of technology. Cooling system of an internal combustion engine involves a complex geometry of cooling jacket. Engine specification along with engine block shape and operating range determine the cooling jacket layout. A cooling jacket is not only intended to carry away heat from engine, but also helps to accomplish the optimal operating temperature at the earliest. It is very difficult to analyze the complete behavior of water jacket experimentally and theoretically, due to complex geometries and flow paths [2]. Vehicle thermal management system had fairly remained constant from last few years. In this field primary targets are to achieve quick engine warm-up, avoidance of overheating or over cooling and temperature maintenance. However recently, the need of improved efficiency had driven higher demand. Also, the engine is desired to operate with less parasitic losses [3]. In actual practice, almost all parts of cooling circuit take part in heat transfer, in other phenomenon which influences the efficiency of cooling system. For example, pressure drop influence the fluid flow rate, which determine the convective heat transfer coefficient. Therefore, there are many physical phenomenon one could model in order to capture the behavior of the system as thoroughly as possible [4].

The main objective of the present research is to prove the feasibility of a cooling system model developed in GT-Suite. GT-Suite is one-dimensional simulation software which plays major role to reduce the lead time as well as overall cost. Flow model used in GT-Suite based to solve the basic equations of thermodynamics and fluid mechanics (generally, the Navier-Stokes equations). The Navier-Stokes equation is the continuity equation and law of conservation of momentum and energy equation. These equations are solved for each element of discretised model separately, either using explicit or implicit schemes [5]. Cooling system with special kind of water jacket is simulated. Due to the complexity of the cooling system it is difficult to achieve the simulation results close to bench test [6]. Total temperature rise through water jacket has been measured and results were compared with test data.

However, one dimensional cooling system thermal fluid analysis enables the study of entire cooling system control and also optimization of piping but it does not provide detailed fluid flow analysis inside water jacket [7]. Coolant circuit consists of numerous components, and 1D thermal fluid simulation is applied to study the temperature behavior of the coolant. For both normal and severe driving conditions automotive designers should design a robust engine cooling system [8]. However, the interaction of the all vehicle components can be very complex, such that, in many cases it is very

Corresponding author: k_vinod@,blr.amrita.edu; adsul.pranita@gmail.com 
difficult to predict how a new thermal management component may interact with entire vehicle power train, especially in terms of fuel economy and emission control. The challenge is to develop simulation models that can help to optimize the vehicle thermal management strategy in effort to find out a proper cost/benefit ratio for new components and control strategy [9]. Prior to the doing any engine water jacket modifications, the coolant flow characteristics such as pressure drop, water jacket wall temperature and velocity must be identified and fixed carefully [11].

Internal combustion engines are also classified according to cooling system, air cooled engines and water cooled engines. In later system water is used as a heat transfer medium which is preferred over air because of its higher specific heat capacity, density and thermal conductivity. It allows water to transfer heat to greater distance compared to less volumetric flow and reduced temperature difference [12]. Adequate temperature management strategies will be beneficial to achieve high NOx conversion level in after treatment system. Splitcooling system and other thermal management measures have potential to reduce $\mathrm{CO}_{2}$ and increase exhaust temperature during cold start simultaneously [13].

\section{METHDOLOGY}

In this paper one-dimensional model of cooling system for diesel engine has been developed in GT-Suite software. The performance prediction through any tool requires so, required input parameters fed to the tool. However, care should be taken with input data to get prediction near to test data. Figure 1 illustrates the methodology followed to develop predictive model. Inputs required

To develop $1 \mathrm{D}$ model main requisites are:

1) $\mathrm{CAD}$ model of an engine

2) Performance details of components

3) Thermostat hysteresis curve

4) Boundary condition data

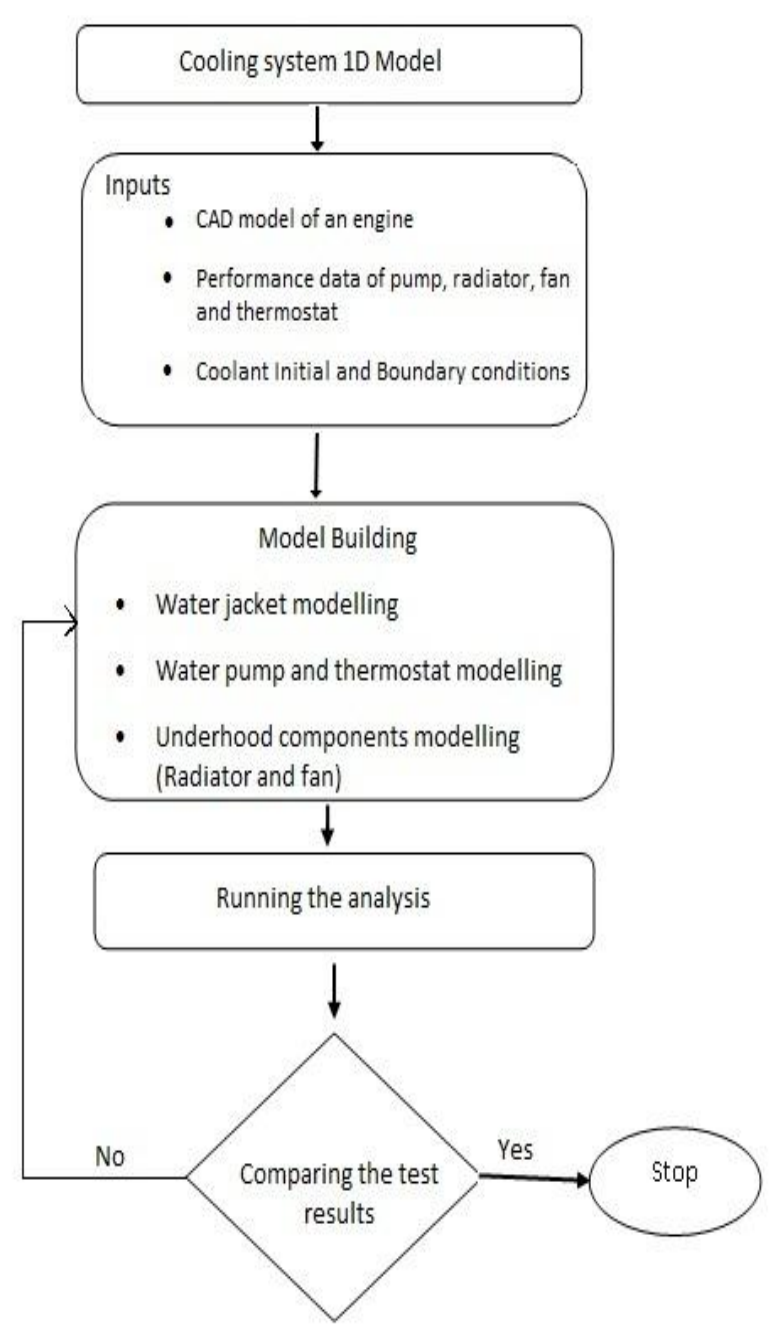

Fig. 1. Methodology adopted to develop $1 \mathrm{D}$ simulation network

CAD model of an engine head and block imported in to the Spaceclaim software to extract cooling jacket. Spaceclaim is the pre-processing tool of GT-Suite. Which is used to define the flow area of coolant. Then flow path of coolant through engine head and block has been extracted [figure 2] and converted it in to the flow splits. Whole core spit divided in to six different flow spilt each one for one cylinder and one inlet to the water jacket and outlet from the water jacket to the thermostat shown in figure 2. Heat transfer coefficient (HTC) taken from the 3D CFD (Computational Fluid Dynamics) model and temperature boundary conditions are taken from the engine performance model which was developed in GT-Power. So again, the accuracy of the complete cooling system model results is depend on the accuracy of engine performance (GT-Power) model and the 3D CFD HTC results. 


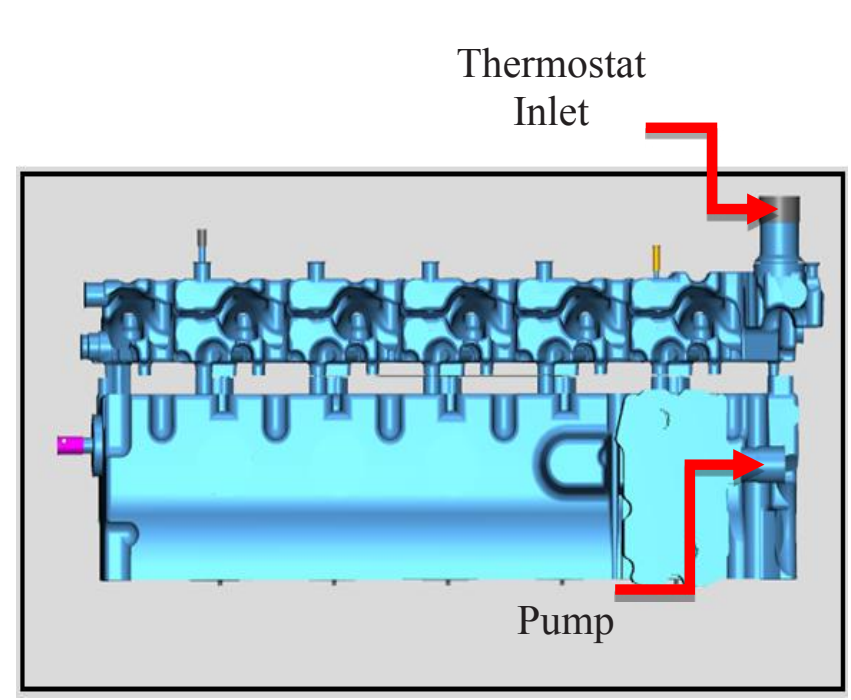

Fig. 2. Extracted core of an engine water jacket

\subsection{Simulation method and Cooling Circuit theory}

GT-Suite is based on one-dimensional tool which represents the flow and heat transfer in piping and other components of a cooling system. Several researchers have used GT-Suite to simulate engine cooling system, lube system etc. $[14,15]$. This tool allows modeling the integration of all heat management activities arising in engine and vehicle development. Also, it provides flexibility to model for advanced concepts and has built in vehicle/engine simulation calculation of thermal loads under different conditions or under any driving cycle. Because of these advantages GT-Suite provides powerful model building facility and reduces user efforts.

Implicit solver is used to solve the Navier-Stokes equation for flow splits to describe how the temperature, pressure and density of a moving fluid are related. For the heat transfer calculation Colburn analogy is used. Always it's not possible to get satisfactory results by Reynolds analogy. Thus, Colburn empirically modified Reynold's analogy which is given by equation, introduces the j-factor.

$$
\begin{aligned}
& S t=\frac{f}{2} \operatorname{Pr}^{-2 / 3} \\
& j=(S t)\left(\operatorname{Pr}^{\frac{2}{3}}\right)=\frac{f}{2}
\end{aligned}
$$

Where, $f$ is the friction factor

The focus of the study is to develop a cooling system model with closed loop including underhood components to predict performance of the cooling system and validate the results with test data. This work will reduce the number of tests thereby saving cost, time and efforts involved. The most important parameters used to validate the analytical results are Limiting Ambient Temperature (LAT) and Coolant out temperature. LAT is defined as the maximum allowable ambient temperature to which the vehicle cooling system can work without failure. For the prediction of a standard cooling system performance of an engine at least two circuits has to be considered. Primary circuit through which heat is taken away from the engine thermal masses to the coolant through convective heat transfer and second is the cooling module in the vehicle where heat is rejected to the air passing over radiator.

Cooling circuit analysis includes, water pump, water jacket, thermostat, radiator and fan. Heat transfer from oil to coolant in oil cooler system has modelled using single flow split, where heat rate input from oil to coolant is given as single value of input which has obtained from the detailed analysis of oil cooler. This extraction of heat from oïl increases coolant temperature but it does not affect much on coolant working as that of it is much effective for oil to release heat to coolant which helps to retain oil properties by maintaining oil temperature in limit. CAC has modelled in the same way as that of oil cooler. Modelling of the cooling components has an advantage of optimizing each component individually irrespective to whole complex system. A simplified diagram of the cooling circuit is represented in Figure 3.

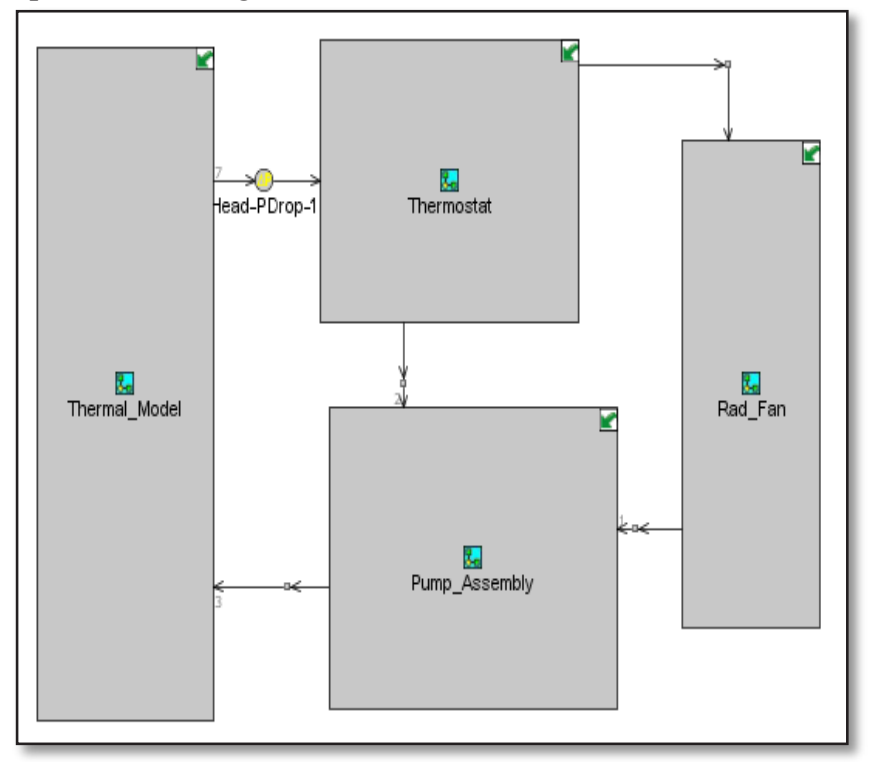

Fig. 3. Scheme of the cooling circuit

A wax thermostat has been used, in which opening of thermostat is temperature bounded. If the coolant temperature is below $82^{\circ} \mathrm{C}$, coolant flows through bypass valve and again circulates to the engine block through pump. To accommodate bypass connection, there are two interdependent thermostat valves namely, 1) Master thermostat and 2) Slave thermostat. The master 
thermostat valve is connected to the radiator and slave thermostat valve by passes the coolant to the pump without flowing through the radiator. To compare test data arrangement has been done to keep thermostat in fully open condition irrespective of the coolant temperature. Fan has been modelled with drive ratio of 1.1 and it is engaged at any flow condition to validate the results with test data. The steady state analysis has been performed for engine cooling system and methodology validated experimentally. The deviation between the test results and analytical results found reasonable.

\subsection{Engine Testing}

The objective of engine testing was to validate simulation tool which has been developed for cooling system performance prediction and also to test the behavior of cooling system of an engine in worst case conditions. The combination of two different conditions such as rated speed and peak torque were used in testing to understand the effect of performance parameters on components on the end results. The details of combination of testing parameters and components are mentioned in Table 1. Vehicle level testing has been performed to test the behavior of cooling system at worst operating conditions; engine tested at rated speed and peak torque conditions. Thermostat has been kept at fully open condition and fan at fully engaged condition with engine irrespective of the coolant temperature.

Table 1. Combination used for cooling trials

\begin{tabular}{|c|c|c|c|}
\hline & & Rated Speed & Peak Torque \\
\hline Engine & & $180 \mathrm{hp}$ & $180 \mathrm{hp}$ \\
\hline Make & & Cummins & Cummins \\
\hline \multirow{3}{*}{ Radiator } & Thickness & 48 & 48 \\
\hline & $\begin{array}{l}\text { Fin } \\
\text { (fpi) }\end{array}$ & 16 & 16 \\
\hline & Core Size & $\begin{array}{l}785 \times 537.2 X \\
48 \mathrm{~mm}\end{array}$ & $\begin{array}{l}785 \times 537.2 \\
X 48 \mathrm{~mm}\end{array}$ \\
\hline \multirow[b]{2}{*}{ Fan } & Pulley ratio & 1.1 & 1.1 \\
\hline & $\begin{array}{l}\text { Blade } \\
\text { Diameter } \\
(\mathrm{mm})\end{array}$ & 596 & 596 \\
\hline
\end{tabular}

The parameters of interest during testing are engine water inlet temperature, engine water outlet temperature before radiator or top tank temperature and ambient temperature to calculate LAT.

$$
L A T=T_{r e f}-T T T+T_{a m b}
$$

$T_{a m b}=$ Ambient temperature

\section{RESULTS AND DISCUSSION}

The model is prepared to solve the steady state condition. The simulation results were compared with test results. It is inferred that, the simulation allows quick calculation and diminutive amount of time to complete the simulation. The calculations can be accelerated with appropriate selection of the initial conditions (temperature of particular parts, system pressure). In our simulation, we focused on unfavorable cases where, underhood cooling circuit is exposed to the highest load.

Table 2 represents the comparison between simulation and test results. There is around $+/-2 \%$ deviation in results. The present model is over predicting the coolant out temperature for rated speed as well as for Peak torque condition. Such results may be owed to the assumption of constant temperature of thermal masses exposed to combustion gases for one engine speed as well as it has considered that heat transfer coefficient is same over all range of temperature.

Considering the equation (2), the heat transfer coefficient is also depends on the thermos physical properties as well as on the geometrical properties, namely hydraulic diameter and velocity.

$$
N u=\frac{h \cdot D}{k}=N u(R e, \operatorname{Pr})
$$

Apart from this also, have to consider the sensitivity error of the sensors and man-made.

\begin{tabular}{|c|c|c|c|c|c|c|}
\hline \multirow[b]{2}{*}{$\begin{array}{l}\text { Sr } \\
\dot{\text { N }} \\
\text { o. }\end{array}$} & \multirow[b]{2}{*}{$\begin{array}{l}\text { Paramete } \\
\text { rs }\end{array}$} & \multirow[b]{2}{*}{ Limit } & \multicolumn{2}{|c|}{$\begin{array}{l}\text { Test } \\
\text { condition }\end{array}$} & \multicolumn{2}{|c|}{ Simulation } \\
\hline & & & $\begin{array}{l}\text { Rate } \\
\text { d } \\
\text { Spee } \\
\text { d } \\
\end{array}$ & $\begin{array}{l}\text { Peak } \\
\text { Torq } \\
\text { ue }\end{array}$ & $\begin{array}{l}\text { Rate } \\
\text { d } \\
\text { Spee } \\
\text { d } \\
\end{array}$ & $\begin{array}{l}\text { Peak } \\
\text { Torq } \\
\text { ue }\end{array}$ \\
\hline 1 & $\begin{array}{l}\text { Ambient } \\
\text { Temperat } \\
\text { ure }\end{array}$ & $21 \sim 39$ & 32.5 & 33.7 & 32.5 & 33.7 \\
\hline 2 & UCL & $<100$ & 78.4 & 88.7 & 79.4 & 90.4 \\
\hline 3 & LCL & & 73.1 & 81.2 & 73.5 & 80.7 \\
\hline \multirow{2}{*}{4} & \multirow{2}{*}{ LAT } & $\begin{array}{l}\text { Rate } \\
\text { speed }>4 \\
6\end{array}$ & 54.1 & & 53.1 & \\
\hline & & $\begin{array}{l}\text { Peak } \\
\text { Torque }> \\
41\end{array}$ & & 45 & & 43.3 \\
\hline
\end{tabular}

Table 2. Comparison of test and simulation results

All the values are expressed in Degree $\left({ }^{\circ} \mathrm{C}\right)$

Where,

LAT is limiting ambient temperature

$T_{\text {ref }}=$ Reference temperature of coolant

$\mathrm{TTT}=$ Top tank temperature 


\section{CONCLUSIONS}

In the present paper a steady state analysis has been performed for six cylinder diesel engine cooling system using GT-Suite 1D simulation software package. The result illustrates that, the maximum deviation between simulation and test result is nearly $+/-2 \%$. The accuracy of the proposed method is depend on the accuracy of the components characteristic in the cooling system as well as on the operating point of a components. It also inferred that, operating point for pump and fan is falling within characteristics data points. Conclusively, this kind of simulation reduces the required time compared to the 3D CFD simulation, as well as efforts and cost required for testing, the accuracy of the results are also in acceptable range. So, such studies will be helpful to reduce analysis time and overall cost. Further, this model can be modified to take in account some more components such as condenser, cabin-heater etc. which can affect the cooling system. In future, this model can be coupled with engine model and the effect of cooling system, on performance parameters like bsfc (brake specific fuel consumption), bmep (brake mean effective pressure), gmep (gross mean effective pressure) and torque of an engine can be observed with running model in duty cycle which will help in understanding the behavior of an engine cooling system as well as engine performance in transient way. Furthermore, GT-Suite is capable of building complete virtual model of a complete vehicle, from cooling system components, transmission system, accessories and tire.

\section{Acknowledgements}

Authors are immensely grateful to Cummins India Pvt. Ltd. for providing necessary facilities to carry out the present research work. We also wish to acknowledge the valuable guidance and encouragement from the Director, Head of the Department of Mechanical Engineering and teachers, Amrita school of engineering, Bangalore, during the work.

\section{Acronyms}

GT- Gamma Technology

GT-ISE - GT- Integrated Simulation Environment

1D- One Dimensional

HTC- Heat Transfer Coefficient

LAT- Limiting Ambient Temperature

FPI- Fins per inch
UCL- Upper Cooling Limit

LCL- Lower Cooling Limit

BSFC- Brake Specific Fuel Consumption

BMEP- Brake Mean Effective Pressure

GMEP - Gross Mean Effective Pressure

\section{References}

1. Umekar, Manvendra M., and D. Govindaraj., No. 2011-26-0087. SAE Technical Paper, (2011).

2. Mulemane, Aditya, and Ravindra Soman, No. 200701-4129. SAE Technical Paper, (2007).

3. Shutty, John, Wolfgang Wenzel, Michael Becker, Stephen Bohan, and Glenn Kowalske, No. 2013-010546. SAE Technical Paper, (2013).

4. Minovski, Blago B., and Lennart Lofdahl, No. 2014-01-0653. SAE Technical Paper, (2014).

5. Bolehovský, Ondřej, and Jan Novotný, Journal of Middle European Construction and Design of Cars 13, no. 3 (2015): 24-32.

6. Soujanya, C., and V. Sundaram., No. 2015-260196. SAE Technical Paper, (2015).

7. Nessim, Waleed, F. Zhang, Zhao Changlu, and Zhu Zhenxia, In International Conference on Mechanical Engineering and Material Science (MEMS 2012), Shanghai, Dec, pp. 28-30. (2012).

8. Masjuki, H. H, Engineering e-Transaction (ISSN 1823-6379) 7, no. 2, pp 127-134. (2012)

9. Keller, Philip, Wolfgang Wenzel, Michael Becker, and Josh Roby, No. 2010-01-0806. SAE Technical Paper, (2010).

10. Kotebavi, V., Shetty, D and Sahu, D, Pollution Research Volume 35, Issue 1, Pages 159-166 (2016)

11. Qasemian, Ali, and Ali Keshavarz, Tehnički vjesnik 23.1: pp 257-264. (2016)

12. Umekar, Manvendra M., and D. Govindaraj, No. 2011-26-0087. SAE Technical Paper, (2011).

13. Honardar, Sharareh, et al., No. 2011-24-0176. SAE Technical Paper, (2011).

14. Mayer, A., et al. Engine intake throttling for active regeneration of diesel particle filters. No. 2003-010381. SAE Technical Paper, 2003.

15. Seider, Gerald, et al., No. 2001-01-1722. SAE Technical Paper, (2001). 